\title{
O GOSTO E AS CONDIC̣ÕES DE SUA REALIZAC̣ÃO: A ESCOLHA POR PEDAGOGIA ENTRE ESTUDANTES COM PERFIL SOCIAL E ESCOLAR MAIS ELEVADO
}

\author{
Cláudio Marques Martins Nogueira* \\ Flávia Goulart Pereira**
}

RESUMO: O trabalho analisa sociologicamente o processo de escolha do curso de Pedagogia da UFMG por alunas com perfil social e escolar mais elevado e que, portanto, teriam, em princípio, em função de seus recursos econômicos e acadêmicos, condições para escolher cursos mais seletivos e vistos como de maior retorno econômico e simbólico. Por meio de entrevistas em profundidade, analisam-se diferentes aspectos das trajetórias sociais e escolares das alunas, que, de alguma forma, podem ter conduzido à decisão final pela Pedagogia. Discute-se, especialmente, em que medida a escolha é fruto de um gosto particularmente forte pela área de Educação e de que modo a manifestação e a realização desse gosto foi favorecida por circunstâncias específicas. Acredita-se que o trabalho contribui para uma relativização das explicações sociológicas sobre a escolha do curso superior, que tendem a considerar o gosto ou as preferências individuais simplesmente como frutos de uma adaptação dos agentes a sua condição social passada ou a sua situação atual de ação.

Palavras-chave: Escolha do Curso Superior; Gosto; Pedagogia.

\section{TASTE AND THE CONDITIONS FOR ITS FULFILLMENT:}

THE CHOICE FOR PEDAGOGY BY STUDENTS WITH HIGHER SOCIAL AND EDUCATIONAL PROFILES ABSTRACT: This study sociologically examines the processes related to the undergraduate students' choices for the Pedagogy course at the Federal University of Minas Gerais - UFMG. The participants are female students whose social and educational profiles would allow for a choice of courses that are seen as more exclusive and with higher economic and symbolic gains. Through in-depth interviews, the author analyzes the different aspects of the participants' social and academic trajectories that may have led to their final decision for Pedagogy. The discussion focuses on the extent to whether the choice for Pedagogy is the result of a particularly strong preference for this field and how the manifestation and fulfillment of this preference has been favored by specific circumstances related to different life background. It is believed that the work has contributed to a relativization of sociological explanations for the choice of undergraduate courses, which tend to consider individual taste or preferences simply as results of the agents adaptation to their past social conditions or to their current social situation.

Keywords: Choice for Higher Education; Taste; Pedagogy.

\footnotetext{
* Sociólogo e Doutor em Educação pela Universidade Federal de Minas Gerais (UFMG); Professor de Sociologia da Educação da Faculdade de Educação da Universidade Federal de Minas Gerais (UFMG) e Pesquisador do Observatório Sociológico Família-Escola (OSFE). E-mail: cmmn@uol.com.br

* *Graduada em Pedagogia pela Universidade Federal de Minas Gerais (UFMG) e Pós-graduada em Psicopedagogia pela Universidade do Estado de Minas Gerais (UEMG).E-mail: pflaviagoulart@hotmail.com
} 
A perspectiva sociológica nos conduz normalmente a uma visão que pode ser considerada desencantada, ou simplesmente realista, das relações entre o gosto ou as preferências individuais e as condições objetivas nas quais estão inseridos os agentes. Seja na tradição da Escolha Racional, na qual a realização das preferências é descrita como resultado de uma análise estratégica, e até certo ponto consciente, por parte do agente, dos custos e benefícios associados a diferentes alternativas de ação, seja na tradição bourdieusiana, em que o ajustamento das preferências às condições objetivas de sua realização é visto como produto de um habitus previamente constituído, chegamos sempre à conclusão de que as escolhas individuais não são a expressão direta de um gosto autônomo, independente, previamente constituído em relação às condições de sua realização. Ao contrário, ambas as tradições teóricas nos mostram que o gosto, as preferências e, em última instância, a própria escolha são resultado de uma espécie de adaptação dos agentes às condições sociais objetivas. Nos termos de Bourdieu (2007; 2003; 1983), aprendemos socialmente a amar o que é possível ou mais provável, dada nossa condição social, e a excluir do universo de nossas aspirações os sonhos impossíveis ou improváveis.

Esse olhar sociológico sobre as escolhas individuais se manifesta de forma clara nas pesquisas sobre a escolha do curso superior'. Essas pesquisas apontam duas conclusões básicas. Primeira, a de que o perfil dos estudantes varia fortemente de acordo com o curso frequentado. Os indivíduos não se distribuem aleatoriamente entre os diversos cursos em função de supostas preferências ou interesses de natureza idiossincrática. Ao contrário, essa distribuição está estatisticamente relacionada a características sociais, perfil acadêmico, etnia, sexo e idade dos estudantes. Segunda, a de que existe um importante e complexo processo de autosseleção na escolha do curso superior. Os indivíduos, via de regra, se antecipam aos processos seletivos formais e já escolhem cursos compatíveis com suas características sociais e escolares.

Sinteticamente, as pesquisas nacionais e internacionais sobre o tema mostram que indivíduos mais novos e com perfis sociais e escolares mais favoráveis tendem a escolher os cursos mais seletivos, prestigiosos e que preparam para as profissões mais rentáveis e de maior status. Indivíduos mais velhos e com características sociais e escolares menos favoráveis tendem, ao contrário, a escolher os cursos de acesso mais fácil 
e que preparam para as profissões menos prestigiosas e rentáveis. A escolha do curso superior está relacionada ainda ao sexo e ao pertencimento étnico dos candidatos ${ }^{2}$.

Neste trabalho, propusemo-nos analisar uma situação que foge, em alguma medida, desses padrões indicados pelas pesquisas. Investigamos o processo de escolha do curso de Pedagogia por indivíduos com perfil social e escolar mais elevado e que, portanto, teriam, em princípio, em função de seus recursos econômicos e acadêmicos, condições para escolher cursos mais seletivos e vistos como de maior retorno econômico e simbólico ${ }^{3}$. Nosso objetivo foi compreender como se constroem essas escolhas estatisticamente improváveis. Esses alunos apresentariam um gosto especialmente forte pelo curso ou pela área de Educação que os faria desconsiderar o baixo prestígio e o baixo retorno econômico socialmente atribuído a essa área de formação? E, nesse caso, como esse gosto teria sido socialmente constituído ao longo de suas histórias de vida? A explicação não estaria propriamente num gosto acentuado pela área, mas em certas particularidades ou contingências de suas trajetórias sociais e escolares, que os teriam afastado do que seria mais previsível para indivíduos com seu perfil social e escolar? Se sim, que particularidades ou contingências são essas, e de que maneiras elas contribuíram para definir a escolha final pela Pedagogia?

O próprio modo como anunciamos essas questões deixa claro que este trabalho não pretende contrapor-se ao olhar desencantado da Sociologia, acima descrito, em prol da defesa de uma suposta autonomia da ação individual, mas apenas compreender de maneira mais complexa as relações entre os "determinismos sociais" e as ações individuais. Para uma compreensão mais ampla do processo de escolha do curso superior, parece importante ir além da simples identificação de correlações entre o perfil típico ou médio dos candidatos e o status dos cursos escolhidos. É interessante compreender como os elementos que finalmente levam à decisão por um curso vão sendo construídos ao longo da trajetória de vida dos sujeitos, em função dos múltiplos laços sociais que eles vão estabelecendo (ou rompendo) e das experiências que vão tendo na família, na escola e em sua rede social mais ampla.

Os gostos, as preferências, os objetivos e, finalmente, as escolhas que os indivíduos fazem na área educacional não podem ser mecanicamente deduzidos de sua posição social de origem. Em primeiro lugar por- 
que os indicadores tradicionalmente utilizados para definir a origem social dos indivíduos (renda, ocupação, nível de escolaridade dos pais, etc.) são insuficientes para se captar a complexidade de cada família. Famílias com um mesmo nível de renda podem atribuir significados e gerir seus recursos econômicos de maneira bastante diferenciada. Pais que desempenham uma mesma ocupação também podem exercê-la de múltiplas formas, inclusive com diferentes graus de sucesso, de ambição profissional e de prazer. O mesmo pode ser dito em relação ao nível de escolaridade. Diante de pais com curso superior, é possível perguntar, por exemplo, que cursos fizeram, de que áreas, em que instituições, com que nível de desempenho acadêmico e com que grau de realização pessoal ${ }^{4}$. Em segundo lugar, mesmo que tivéssemos uma caracterização mais detalhada da origem social dos indivíduos, teríamos de considerar que a socialização - e, particularmente, a transmissão familiar do capital cultural e das expectativas e aspirações em relação ao futuro, decisivas para os processos de escolha na área educacional - não é um processo mecânico, automático, totalmente previsível. Os indivíduos incorporam apenas parte das características de seus grupos familiares e, ainda assim, as reelaboram e as mesclam com influências recebidas de outros grupos e de outras instâncias de socialização ${ }^{5}$

Como salienta Lahire $(2002 ; 1999)$, tudo depende então da escala de análise adotada. De um ponto de vista macroscópico, sem dúvida, podemos dizer que certas atitudes e comportamentos são mais prováveis entre indivíduos com origem social mais elevada e que outros são mais comuns entre aqueles com origem menos favorável. Essas regularidades são incontestáveis e constituem a própria base do raciocínio sociológico. Se estivermos interessados, no entanto, em compreender sociologicamente comportamentos de indivíduos específicos, teremos necessariamente de nos situar numa outra escala de análise e estar atentos a dimensões que são deliberadamente excluídas das investigações que visam à identificação de regularidades estatísticas. Nesse caso, precisaremos observar a multiplicidade de influências - variáveis em termos de precocidade, intensidade e regularidade e nem sempre coerentes entre si - a que um indivíduo se submete ao longo do seu processo de socialização. Teremos de considerar a rede de relações sociais em que esse indivíduo esteve inserido ao longo de sua trajetória e que pode ou não se manter, e em maior ou menor grau, no seu contexto atual de ação. Precisaremos ainda avaliar o papel das con- 
tingências, o peso que podem ter assumido certos acontecimentos ou eventos singulares na definição do percurso individual.

Foi nessa segunda escala de análise que procuramos nos situar ao elaborar este trabalho. Investigamos como as condições que levam à escolha final pela Pedagogia vão sendo construídas ao longo das trajetórias pesquisadas, a partir da rede de relações estabelecidas, dentro e fora da família, com outros sujeitos e em função de acontecimentos variáveis, produzidos por ações anteriores dos próprios indivíduos ou totalmente independentes destas. Analisamos, especialmente, de que forma e em que medida pode ter se constituído, na história de vida desses indivíduos, o gosto pela área de Educação e que papel esse gosto pode ter assumido na definição da escolha atípica aqui considerada: Pedagogia por alunos com perfil social e escolar mais elevado.

São analisadas oito entrevistas semidiretivas realizadas em 2006, com estudantes do primeiro ano de Pedagogia, aleatoriamente selecionados entre os 22 identificados como tendo perfil social e escolar mais favorável $^{6}$. Para se definir o perfil social foram consideradas a renda, a ocupação e a profissão dos pais, a posse de bens materiais e a avaliação dos próprios sujeitos sobre a situação econômica de suas famílias na infância e na adolescência. Para se definir o perfil escolar dos alunos, foram considerados o nível de escolaridade dos pais e avôs, o tipo de escola frequentado (pública ou privada), o turno, o número de reprovações, a idade de conclusão do ensino médio e a avaliação dos próprios sujeitos sobre seu desempenho como alunos nos ensinos fundamental e médio.

De modo geral, as oito alunas estudadas são filhas de famílias com situação econômica e com nível de escolaridade significativamente superior ao observado para o conjunto dos alunos de Pedagogia no momento da pesquisa, além de terem apresentado trajetórias escolares mais favoráveis do que a média de seus colegas. Vale a pena salientar, no entanto, que, entre os casos analisados, alguns se destacam mais pelo perfil social e outros pelo perfil escolar, não havendo, portanto, plena homogeneidade entre eles. 
Oito trajetórias rumo à Pedagogia:

diferentes articulações entre preferências individuais e condições objetivas de sua realização

Como estratégica de estruturação da análise, dividimos as oito entrevistas em quatro pares, a partir da identificação da existência de traços significativos em comum. Foram considerados, para esta classificação, principalmente, o grau de antecedência com que o curso foi escolhido, as razões pelas quais a decisão pelo curso foi mais ou menos adiada ao longo da trajetória e o gosto maior ou menor manifestado pela profissão. Assim, nos casos do primeiro subgrupo, há um gosto acentuado pela área educacional, mas que só é reconhecido pelas entrevistadas (levando à escolha pela Pedagogia) tardiamente, após enfrentarem uma série de problemas pessoais e profissionais. Nas entrevistas agrupadas no segundo subgrupo, o gosto pela área de educação também é forte e foi reconhecido desde sempre. Ainda assim, a decisão pela Pedagogia foi adiada, sobretudo, pela forte resistência ao curso por parte de parentes e conhecidos. No terceiro subgrupo, reunimos dois casos em que o gosto pela área educacional levou as alunas diretamente, sem nenhuma postergação, à Pedagogia. Finalmente, no quarto subgrupo, encontram-se os dois casos nos quais a escolha da Pedagogia não parece motivada por um gosto marcante pela área. Ao contrário, essa decisão parece resultar de dificuldades objetivas encontradas para se realizar outros cursos. Parece que encontramos nesses últimos casos, novamente, algo próximo do que Bourdieu chamava de "escolha pelo possível”.

\section{Subgrupo 1: Camila e Renata -}

\section{Pedagogia como saída para crise pessoal e profissional}

Estes dois primeiros casos são aqueles em que o perfil social e escolar das alunas se destaca mais em relação à média dos estudantes de Pedagogia. A primeira aluna vem de uma família de classe média, com alto nível de escolaridade: o pai é médico, com doutorado em andamento; a mãe é formada em Letras e tem uma escola de educação básica; três dos avós têm curso superior, sendo um deles médico cirurgião, e outro, aposentado como procurador e professor de Direito da UFMG. A entrevistada sempre estudou em colégios particulares de prestígio e foi ótima aluna. A mãe e também o avô materno acompanhavam e cobravam muito o desempenho escolar da estudante. 
A segunda aluna vem de uma família com nível de escolaridade mais baixo: ambos os pais com ensino médio completo. De qualquer forma, eles tiveram sucesso em suas áreas de atuação profissional (Contabilidade e Eletrotécnica), o que fez, segundo a aluna, com que a família tenha tido, na maior parte do tempo, boa situação econômica. A aluna foi mantida em uma escola particular de boa reputação durante todo o ensino fundamental e médio. Os pais foram capazes também de sustentá-la numa faculdade particular durante o período em que ela fez seu primeiro curso superior, Psicologia, na PUC Minas. A estudante relata que durante toda a sua trajetória foi uma aluna muito boa e que, segundo opinião da sua mãe, dedicava-se até excessivamente aos estudos.

Nesses dois casos, as alunas tinham, portanto, claramente, condições econômicas e acadêmicas para escolher cursos mais seletivos e socialmente valorizados do que a Pedagogia, e foi exatamente isso o que elas inicialmente fizeram. Em ambos os casos, a Pedagogia só surge bem mais tarde, como resposta a uma crise pessoal gerada pela inadaptação a diferentes cursos iniciados (Camila) ou pela dificuldade de inserção profissional após a conclusão de um primeiro curso (Renata).

Camila diz que, até a oitava série, pensava em ser médica, depois resolveu que queria Engenharia de Materiais. No momento do vestibular, escolheu e foi aprovada em Engenharia Química, na UFMG, e Arquitetura, em uma faculdade particular. Começou os dois, mas acabou se desencantando com ambos os cursos e os abandonando. Iniciou então Administração em outra faculdade particular, mas também abandonou, em parte pela pressão dos pais, que queriam a UFMG. Resolveu então voltar à Arquitetura, agora na UFMG. Fez o vestibular, também foi aprova$\mathrm{da}$, inicialmente gostou do curso, mas depois, sentindo-se pouco apta em relação à dimensão criativa exigida pelas disciplinas e por essa área profissional, decidiu trancá-lo.

O curso de Pedagogia começa então a ser cogitado e a escolha é feita num momento de intensa crise, em que a aluna, após ter começado e se decepcionado com vários cursos, está se sentindo cansada e acha que é tarde para abandonar Arquitetura na UFMG e partir para algo de que ela não sabia se iria gostar. Nesse momento, decide trabalhar um pouco na escola da mãe para ver se o contato com as crianças a ajuda a desenvolver seu lado mais criativo, e acaba inesperadamente se apaixonando pela profissão de professora. Nas palavras dela: "Aí eu apaixonei. 
Apaixonei. Gente, isso tá o tempo todo do meu lado e eu não tinha visto. Acho que eu fiquei tentando negar desde o começo e na verdade era uma coisa que, como diz meu pai, eu me encontrei!"

No caso de Renata, a escolha inicial por Psicologia é atribuída pela aluna ao fato de fazer terapia há muito tempo e também de ter tido uma boa professora de Religião, formada em Psicologia. A aluna alega também que escolheu esse curso por imaginar que não era uma profissão burocrática e rotineira, a cada dia teria pacientes diferentes e com problemas diferentes. Antes de se decidir por Psicologia, no entanto, havia pensado em fazer licenciatura em Química, o que já indica a existência de um interesse mais antigo pela área da docência.

A escolha por Pedagogia ocorre sete anos após a conclusão do curso de Psicologia. A aluna relata que encontrou muitas dificuldades para se inserir profissionalmente no campo da Psicologia. Ficou muito tempo desempregada, teve de fazer pequenos cursos profissionalizantes (como banho e tosa de cachorros) e trabalhar em funções precárias e pouco gratificantes, todas distantes da área em que havia se formado. Psicologicamente, a aluna diz que passou por maus momentos, ficando um tanto desesperada e deprimida. A situação ficou ainda mais delicada com a piora da situação financeira familiar. A aluna, já com 30 anos, sentia-se então pressionada a ajudar financeiramente a família e, para isso, decidiu fazer outro curso superior, Pedagogia, na UFMG. Em relação à escolha desse curso, ela diz: "Pensei assim, faria Pedagogia, porque é uma coisa que eu sempre tive vontade de trabalhar com escola, só que eu nunca tinha pensado nisso. Engraçado assim porque eu sempre gostei, sempre tive vontade de fazer, mas nunca tinha pensado nessa hipótese, né?"

Nesses dois casos, é interessante observar como as próprias alunas estranham o fato de não terem pensado antes em fazer Pedagogia. No caso de Camila, a mãe é professora e possui uma escola de Educação Básica na qual ela estudou até a quarta série. Segundo ela, mesmo quando começou a estudar em outras escolas, quase todas as tardes ficava estudando na escola da mãe, tendo, portanto, muito precocemente, tido todas as oportunidades de conhecer e se identificar com a área de Educação. Renata, por sua vez, afirma que sempre gostou do ambiente escolar, que a escola onde estudou era muito boa e que, como era ao lado da casa dela, ficava lá quase o dia todo, participando de inúmeras atividades. Diz que sempre teve vontade de trabalhar nessa escola e que chegou a pensar em 
fazer magistério no ensino médio. A Pedagogia, no entanto, não chegou inicialmente a ser cogitada.

Camila sugere uma explicação psicológica para a sua ida tardia para a Pedagogia: "Acho que eu sempre admirei muito o meu pai, né? Aí eu ficava meio tentando negar a minha mãe, né?". Ela afirma que apesar de estar sempre lá, não gostava muito de frequentar a escola da mãe e que nem pensava em ser professora. A profissão e o universo paterno, ao contrário, teriam atraído a entrevistada desde a infância. Até a oitava série, com a decisão de ser médica, como o pai, depois, com a escolha por Arquitetura, área que o pai adora (chegando inclusive a desenhar projetos) e administração (área em que o pai também atua há muitos anos, dentro de um plano de saúde). O próprio gosto pela matemática, relatado pela aluna, coincidiria com a facilidade do pai com a matemática e os números em geral. Cabe notar, finalmente, que a escolha por Pedagogia é bem vista e, num certo sentido, atende aos gostos do pai, um apaixonado por Piaget e outros teóricos da Educação, ao mesmo tempo que, curiosamente, desagrada a mãe educadora.

Essa interessante explicação psicológica talvez precise, no entanto, ser no mínimo enriquecida por uma explicação sociológica, que chama atenção para o grau de prestígio diferenciado dos diversos campos profissionais entre os quais a entrevistada se divide (SETTON, 1999). Temos, de um lado, Medicina, Engenharia Química, Arquitetura e Administração, de outro, Pedagogia. Como foi dito inicialmente, essa aluna vem de uma família de classe média bastante escolarizada, com pai e avós tendo seguido profissões de prestígio. Havia, na família, sobretudo por parte da mãe e do avô materno, forte pressão por um bom desempenho escolar e por uma trajetória profissional de destaque. Além disso, a aluna estudou em colégios também de classe média, nos quais conviveu com outros jovens que, em sua grande maioria, escolhiam profissões de maior prestígio social. Diante desse universo, não é difícil entender a tendência da aluna de negar a área de Educação e buscar outras áreas.

Essa explicação, de cunho mais sociológico, certamente também pode, em grande medida, explicar o comportamento de Renata, que, em seu primeiro vestibular, escolheu Psicologia e nem sequer cogitou fazer Pedagogia, mesmo tendo manifestado gosto precoce pela profissão docente e pelo ambiente escolar.

Em ambos os casos, as experiências intensas vividas pelas alunas no universo escolar (a escola da mãe, no caso de Camila; a escola onde 
estudou, no caso de Renata) não foram suficientes para que elas escolhessem, já no seu primeiro vestibular, o curso de Pedagogia. Essas experiências só são recuperadas e passam a justificar a reorientação profissional em direção à área de Educação a partir do momento em que suas escolhas iniciais se mostraram mal-sucedidas: dificuldade de adaptação a diferentes cursos, no caso de Camila; dificuldade de inserção no campo profissional, no caso de Renata.

Em síntese, é possível dizer que, em seu primeiro vestibular, as alunas se comportaram de acordo com o que seria sociologicamente mais previsível para jovens com seu perfil social e escolar: escolheram cursos de maior prestígio e nem cogitaram em fazer Pedagogia. No caso de Camila, nem mesmo o fato de a mãe ser uma bem-sucedida profissional da área da Educação foi suficiente para alterar essa decisão. Do mesmo modo, no caso de Renata, não bastou ter tido experiência escolar intensa e ter desenvolvido uma clara identificação com a área de Educação para se decidir por Pedagogia ou outra licenciatura. Em ambos os casos, foi preciso surgir algo mais sério, um impasse, uma crise, para que a Pedagogia surgisse como uma rota alternativa, uma espécie de refúgio seguro, diante das dificuldades encontradas na trajetória inicialmente prevista.

Finalmente, cabe ressaltar as relações complexas que se manifestam nesses dois casos entre escolha e gosto. Apesar de não ter sido a escolha inicial das alunas, a opção por Pedagogia, quando ocorre, é justificada, em ambos os casos, como expressão de um gosto autêntico pela profissão docente. O que é interessante observar é que, nos dois casos, esse gosto, de alguma forma, parece já estar presente no momento do primeiro vestibular das alunas, embora tenha sido reprimido ou, em outras palavras, não tenha encontrado condições favoráveis para se realizar. Camila, quando descreve sua "paixão" pela profissão docente, afirma que, na verdade, sempre tentou negar seu gosto pela área de Educação. Renata, por sua vez, diz que sempre teve vontade de trabalhar em escola, mas que não havia pensado na hipótese de fazer Pedagogia. Se essa interpretação está correta $^{7}$, o gosto pela área sempre existiu e só não se converteu antes em uma escolha efetiva em função do desprestígio da Pedagogia, particularmente, no meio social dessas alunas. 


\section{Subgrupo 2: Fernanda e Daniele -}

\section{Realização adiada de um gosto socialmente reprimido}

O perfil social e escolar dessas duas alunas também se destaca da média dos alunos de Pedagogia. Os pais de Fernanda, embora não tenham nível de escolaridade tão elevado (ensino médio incompleto), conseguiram, atuando como comerciantes, propiciar à família uma boa condição econômica. Fernanda estudou em escolas particulares de prestígio, diz que foi boa aluna e concluiu o ensino médio sem atrasos. Os pais de Daniele possuem curso superior, Psicologia e Geografia/História, embora não atuem nessas áreas. A família tem situação financeira muito boa. A aluna estudou parte do ensino fundamental e todo o ensino médio numa escola particular, também foi boa aluna e concluiu o ensino médio sem atrasos.

Assim como os anteriores, esses dois casos também se caracterizam por uma escolha relativamente tardia da Pedagogia. Diferentemente do primeiro subgrupo, no entanto, as duas alunas aqui entrevistadas não chegaram a iniciar ou fazer outros cursos superiores. Elas apenas prestaram outros vestibulares antes do de Pedagogia, o que as fez adiar em um ou dois anos a entrada nesse curso.

O que chama mais atenção nesses casos é a existência de um forte gosto pela área de Educação e de uma vontade de ser professora que se manifestam desde a infância. Daniele diz que sempre quis trabalhar com crianças e que, portanto, o curso a ser escolhido deveria mesmo ser Pedagogia. "De criança assim, quando eu era bem mais nova, eu sempre quis ser professora." "... nó... adoro, amo, sabe? Num quero trocar de jeito nenhum!”. De forma semelhante, Fernanda diz que sempre quis ser professora e que, mesmo que tenha pensado em outros cursos, no fundo, o que desejava mesmo era ser professora. "É engraçado assim... eu sempre quis ser professora!" "Eu falava... a gente fala outras coisas, mas assim que eu me lembre mesmo, era ser professora!"

Em que pese a existência desse gosto precoce e aparentemente bastante genuíno pela área de Educação, quando chegam ao vestibular, ambas as alunas optam inicialmente por outros cursos. Daniele fez o vestibular para Enfermagem, não tendo sido aprovada. Questionada sobre a razão de ter escolhido esse curso, ela diz que "quando você fala em fazer Pedagogia todo mundo, né, torce o nariz e tal, então falei assim, vou tentar Enfermagem. Nem era o que eu queria assim...”. É importante consi- 
derar também que Daniele já tinha uma irmã fazendo um curso de prestígio na área de saúde, Odontologia, na UFMG, o que parece tê-la influenciado. Já Fernanda, que também tem um irmão que cursa Enfermagem na UFMG, fez vestibular para os cursos de Enfermagem, Fonoaudiologia e Nutrição, não sendo aprovada. A aluna justifica essas primeiras escolhas dizendo: "da primeira vez eu não... eu não escolhi Pedagogia porque lá em casa... ah! por que que você não faz Direito? Por que que você não faz num sei o quê? Ah... Medicina! Faz isso... faz aquilo! Vai ser professora? Então eu tive dificuldade pra me afirmar naquilo que eu gostava, naquilo que eu queria...".

Nesses dois casos, fica claro, portanto, como o desprestígio social da profissão inibe ou pelo menos adia a escolha por Pedagogia entre alunos com perfil social e escolar mais elevado. Fernanda descreve todo um conjunto de resistências vivido no seu meio social “... por exemplo, tem amigas minhas que ah... Pedagogia, né? Assim, me desvaloriza!”. Da mesma forma, Daniele mostra: "Minha tia ficava assim: ah mais Pedagogia? Ce vai sofrer... "Nossa, cê vai sofrer de mais, coitada!". As duas alunas atribuem claramente o adiamento da entrada na Pedagogia à resistência dos familiares em relação ao curso e à profissão de professora. O pai de Fernanda, por exemplo, dizia que ela ia fazer um curso para ser babá de criança e o pai de Daniele dizia ser este um curso de esperar marido: "Eu sempre tive vontade de fazer Pedagogia, mas eu falava isso lá em casa e meu pai... eu falava: pai, vou fazer Pedagogia, ele ficava assim: hum... curso de esperar marido, ele nunca gostou... assim deu fazer isso não"s.

Para chegarem a escolher Pedagogia, as alunas precisaram, portanto, num primeiro momento, vencer, de alguma forma, as resistências em relação ao curso. Daniele afirma ter escolhido o curso somente depois de ter sido encorajada pela supervisora da escola onde estudava e por uma tia, que dizia que tinha tudo a ver com ela e ainda que não a imaginava em outra área. Já Fernanda afirma só ter tido coragem de assumir para a família que queria fazer Pedagogia depois de um ano de terapia. Em relação a essa terapia, ela diz: "me ajudou a... a me afirmar para escolher o curso que eu queria de verdade".

Em relação a Fernanda, é interessante observar como ela modifica, ao longo do tempo, sua forma de lidar com as resistências sociais ao curso de Pedagogia. Segundo ela, antes da terapia e da entrada no curso, 
aceitava e, de alguma forma, até participava das brincadeiras pejorativas do pai e de outras pessoas em relação ao curso de Pedagogia. Depois, passou a rejeitá-las:

só que assim, até hoje ele (o pai) brinca sabe? Ah, ela faz Pedagogia! Vai ficar limpando nariz de meleca de menino! Eu já mostrei pra ele que eu não gosto, que eu quero é isso, pra ele ter respeito, que se ele não tiver respeito com minha profissão que é meu pai, quem vai ter? ... antes se meu pai falasse, eu ficava na minha. Hoje não. Eu falo: ué? Por quê? Que que tem? Qual o problema? E antes eu não acreditava também, então, é... não... não acreditava também... na Pedagogia, que era o que eu queria e também ficava na minha e acabava criticando também....

A escolha da Pedagogia, nesses dois casos, só parece ter sido possível, portanto, em função da existência de um gosto pela área e pela profissão de professor suficientemente forte para superar os preconceitos e oposições em relação à profissão. Não se pode esquecer também que circunstâncias específicas contribuíram para que esse gosto acabasse por prevalecer. No caso de Fernanda, a influência de uma tia e a terapia parecem ter sido de grande importância. Já em relação a Daniele, o fato de ter ajudado no trabalho com crianças na escola onde estudava e o incentivo da supervisora dessa escola também parecem ter sido determinantes.

Assim como nos dois casos analisados no primeiro subgrupo, as alunas aqui escolheram inicialmente cursos de maior prestígio, mais aceitáveis no meio social a que elas pertencem. É possível dizer que elas estavam seguindo o que seria mais previsível para alunas com seu perfil social e escolar. A reorientação em direção à Pedagogia só ocorre quando suas trajetórias são confrontadas com um obstáculo: a reprovação no vestibular. É somente nessas circunstâncias que o antigo gosto pela área e pela profissão de professor tem condições de se reafirmar.

Mais uma vez, vemos relações complexas entre o gosto e as circunstâncias objetivas de sua manifestação. O gosto dessas alunas pela área de Educação seria efetivamente tão forte que seria capaz de se impor em qualquer circunstância? Se sim, por que elas não escolheram Pedagogia no seu primeiro vestibular? Por outro lado, o que teria ocorrido caso elas tivessem sido aprovadas nos vestibulares para os outros cursos? Será que elas manifestariam, atualmente, da mesma forma, um gosto acentuado pela profissão docente? Em síntese, mais uma vez, permanecem dúvidas 
sobre o peso que se pode atribuir ao gosto como fator explicativo das escolhas profissionais. Ao mesmo tempo que ele é algo que antecede e supostamente determina as escolhas, é também fator maleável, que se ajusta às circunstâncias objetivas, inclusive aos fracassos resultantes de escolhas anteriores.

\section{Subgrupo 3: Gabriela e Marina - uma decisão mais precoce}

Gabriela tem pai com ensino médio completo e mãe com curso superior, Enfermagem. A aluna diz que a família sempre teve boa situação econômica, o que é atestado por uma renda acima de dez salários mínimos e pelos bens de conforto presentes na residência. Gabriela sempre estudou em escolas particulares, sendo, segundo ela, uma aluna muito boa no ensino fundamental e no ensino médio, que foi concluído aos 17 anos.

Marina tem pai com ensino médio completo e mãe com ensino superior incompleto, ambos exercendo cargos gerenciais em empresas transportadoras. A situação econômica da família é similar ou mesmo um pouco superior à da primeira aluna. Marina sempre estudou em escolas públicas consideradas boas: uma escola estadual, no ensino fundamental, e o CEFET-MG, no ensino médio, concluído aos 18 anos.

Esse subgrupo caracteriza-se pelo fato de essas estudantes terem escolhido o curso de Pedagogia mais precocemente e pelo forte gosto que elas dizem ter pela área de Educação. Quando questionada sobre seu processo de escolha do curso superior, Gabriela declara: "Eu sempre quis Pedagogia! No segundo ano, eu já tinha decidido mesmo!" Já Marina parece ter tido um pouco mais de dúvida. Pensou em Engenharia, Economia, Administração e Pedagogia, e diz ter optado por essa última em função do que mais gostava. Para essa escolha, segundo a estudante, questões como a boa relação que ela sempre teve com professores e o gosto pelo ambiente escolar foram fundamentais. Marina conclui dizendo: "Eu sempre fui apaixonada pela educação na verdade!"

Vale notar que tanto Gabriela quanto Marina só prestaram vestibular para o curso de Pedagogia, no qual foram aprovadas com elevada pontuação (indicando que poderiam, objetivamente, ter escolhido outros cursos), já em seu primeiro vestibular. Nos dois casos, o gosto pela Pedagogia é relatado primeiramente a partir de uma grande admiração e 
familiaridade com o que elas chamam de "ambiente escolar". Sobre esse aspecto, Gabriela relata: "Eu não sei se é porque eu sempre gostei do ambiente escolar... Talvez pode ser por isso que eu só tenho vontade de trabalhar nesse ambiente!" Marina também aponta ter feito essa escolha principalmente "por gostar do ambiente escolar, da educação". No caso de Marina, cabe apontar o bom relacionamento que ela tinha com a avó, professora, a qual, mesmo sem tê-la incentivado diretamente, parece ter tido influência sobre sua escolha profissional.

Um aspecto que, em especial, chama a atenção, no caso dessas estudantes, é o gosto pela área de exatas, o que, em certo momento, gerou alguma dúvida entre a escolha de um curso dessa área ou o de Pedagogia. No caso de Gabriela, essa dúvida permaneceu por um tempo menor. Porém, em relação a Marina, esse gosto ainda gera algum tipo de desconforto, uma vez que a estudante declara estar sentindo falta de estudar matemática, apontando ainda o desejo de, mais tarde, prestar novo vestibular para o curso de Economia.

Outro ponto comum é a forte resistência da família em relação à escolha da Pedagogia. Falando sobre seu pai, Gabriela diz: "Ele queria que eu fizesse Medicina, Odontologia! Eles (os pais) nunca aprovaram eu ter feito Pedagogia não!” Da mesma forma, Marina relata que sua mãe dizia: "Marina, mas por que você vai fazer Pedagogia? Gostaríamos que você fizesse alguma coisa que fosse muito além disso, que fosse muito mais". Segundo essas estudantes, era comum escutar seus pais e outras pessoas próximas dizerem que, se escolhessem Pedagogia, estariam desperdiçando o potencial delas. Sobre esse aspecto, Marina declara: "Todo mundo assim... parava e me perguntava: Marina, por que você vai fazer Pedagogia? Cê tem potencial pra muito mais! Ouvi isso inúmeras vezes! Que eu tinha capacidade pra muito mais..."

As duas alunas parecem responder a essas expectativas sociais elevadas manifestando alto nível de aspiração em relação às suas carreiras acadêmicas na área de Educação. As duas apontam o desejo de cursar mestrado e doutorado. Gabriela aponta inclusive que esse foi um dos motivos que a ajudou na escolha desse curso: "Eu acho que a Educação é uma área muito interessante, acho que a gente ainda tem muito o que pesquisar, pesquisar mesmo a questão da educação". Já Marina tem uma resposta pronta para quando as pessoas a questionam sobre seu potencial acadêmico: "Vou fazer meu mestrado, vou fazer doutorado, vou dar aula 
na faculdade e vou ser Ministra da Educação! Eu sei que eu tenho potencial pra muito mais!"

A pressão dos familiares, nesses dois casos, assim como nos casos analisados nos dois primeiros subgrupos, parece estar claramente relacionada ao perfil e à trajetória escolar das alunas. Ambas sempre tiveram bom desempenho e estudaram em escolas particulares ou públicas de destaque. Além disso, a facilidade e o gosto relatado pelas alunas por uma área distante da Pedagogia, como a de exatas, indicam condição privilegiada diante do vestibular: as alunas não estariam presas a um leque restrito de opções. O fato de as alunas terem sido aprovadas na UFMG, em seu primeiro vestibular, e com pontuação significativamente superior à mínima necessária para ingresso no curso, também demonstra seu bom perfil escolar.

Temos, portanto, dois casos em que, claramente, não se operou a lógica da "escolha do possível". As alunas poderiam ter escolhido cursos de maior prestígio e é exatamente isso o que surpreende e incomoda os familiares e amigos. O gosto pela área de educação antecede, nesses dois casos, de maneira inquestionável, o momento da escolha do curso superior. A opção pela Pedagogia não surge tardiamente, como uma adaptação das preferências às oportunidades objetivas, mas, ao contrário, resulta de um gosto precoce e realmente forte, capaz inclusive de vencer os preconceitos e as resistências vividos pelas alunas em sua família e no seu meio social mais amplo.

\section{Subgrupo 4: Telma e Amanda - a escolha pelo possível?}

A mãe de Telma é Pedagoga aposentada, tendo trabalhado muito tempo como orientadora, no Centro Pedagógico da UFMG. O pai é formado em Administração e Economia, tendo se aposentado como auditor fiscal da Receita Federal. Segundo a aluna, a situação econômica da família sempre foi boa. Telma estudou até a sexta série no Centro Pedagógico e, depois, em escolas particulares do interior, para onde se mudou com a família. Diz ter sido, durante toda a trajetória escolar, uma aluna mediana. De qualquer forma, concluiu o ensino médio sem reprovações, aos 17 anos.

Amanda é filha de pai economista e mãe arquiteta. A aluna afirma que a situação econômica da família sempre foi muito boa. Sempre 
estudou em escolas particulares de relativa reputação. Do mesmo modo que Telma, diz que sempre foi uma aluna apenas mediana, o que também não a impediu de concluir o ensino médio aos 18 anos, sem reprovações.

Assim como nos casos analisados nos dois primeiros subgrupos e diferentemente do que vimos no subgrupo anterior, essas duas estudantes escolheram o curso de Pedagogia mais tarde. O que diferencia esse subgrupo de todos os anteriores, no entanto, é o fato de essas alunas relatarem não ter existido, em nenhum momento anterior de suas trajetórias, um gosto ou uma admiração em relação a esse curso e/ou ao campo de atuação profissional. Ao contrário, ambas declaram que nunca haviam tido vontade de estudar ou trabalhar na área de Educação.

Como veremos, a escolha do curso, nesses dois casos, parece, portanto, estar relacionada menos à realização tardia de um gosto precoce, socialmente reprimido (como nos dois primeiros subgrupos), e mais a um ajustamento, até certo ponto forçado, das preferências às condições objetivas de sua realização. As alunas encontraram dificuldades para realizar outras alternativas e acabaram se direcionando para a Pedagogia. A hipótese de uma "escolha pelo possível" surge, portanto, como bastante plausível para se explicar esses casos.

Telma, embora afirme sempre ter tido vontade de trabalhar com a área social, diz ter escolhido a Pedagogia "por último". "Eu não sei se tinha uma resistência com a Pedagogia... É um curso mais... sei lá... mais caído". Essa mesma estudante afirma ainda que não tem vontade de ser professora, mas que "aceitaria ser", caso fosse em um lugar em que realmente se precisasse, citando o exemplo do Vale do Jequitinhonha. Amanda é ainda mais direta: "Eu tinha horror em ser professora! Eu nunca pensei em ser professora, nunca!” No caso dela, o interesse pela Pedagogia só surge quando a estudante, por ocasião de um trabalho voluntário, tem contato com uma escola pública na região onde morava. No entanto, mesmo após a decisão de cursar Pedagogia, a estudante declara: "Eu entrei pra Pedagogia meio com preguiça... eu vou fazer, mas se eu não gostar, eu vou sair".

É importante notar que essas estudantes apresentam perfil escolar um pouco menos favorável do que as demais analisadas neste artigo. Elas têm em comum uma trajetória escolar marcada por várias mudanças de escola, o que talvez ajude a explicar algumas das lacunas apontadas por elas em sua formação acadêmica. Cabe observar ainda que, em vários 
momentos das entrevistas, as estudantes se declaram alunas medianas, com investimento escolar relativamente baixo, apontando limitações acadêmicas significativas em algumas áreas, como, por exemplo, a matemática.

No que se refere às suas fragilidades acadêmicas, as estudantes têm inclusive declarações muito próximas. Telma, em vários momentos da entrevista, declara: "Eu sempre fui uma aluna média, medíocre. Nunca fui de me sobressair demais não. Agora, quanto ao rendimento, é isso. Eu era média!" E Amanda também relata esse mesmo comportamento mediano, afirmando: "Eu era média. Dentro da média. E eu... assim, até pegava minhas recuperações, mas sempre passava. Então tava bom, entendeu?"

As limitações acadêmicas das duas alunas parecem ter se manifestado no momento do vestibular. Amanda realizou, inicialmente, sem sucesso, vestibulares para Ciências Sociais e História, na UFMG. No ano seguinte, tentou vestibular novamente na UFMG, agora para o curso de Pedagogia, mesmo após a aprovação em História em uma faculdade particular.

A situação de Telma foi mais delicada. Essa estudante opta por Pedagogia num momento de muita cobrança, tanto pessoal quanto familiar e social, por uma aprovação no vestibular, uma vez que já havia sido reprovada para outros cursos, a saber, Direito, Arquitetura, Ciências Sociais, Design Gráfico, Publicidade, Turismo e Psicologia.

No caso dessas alunas, as lacunas e fragilidades em sua formação limitaram, inclusive, desde o primeiro vestibular, o leque de opções considerado. No caso de Telma, são evitados alguns cursos, em especial os da área de exatas. Dentro dessa prévia seleção, a aluna opta, inicialmente, por cursos mais seletivos e socialmente mais valorizados, e, após os insucessos no vestibular, são incluídos entre suas opções os cursos de Serviço Social (que ela realiza simultaneamente) e Pedagogia. Assim, Telma, em um discurso que se pretende realista, afirma: "Oh, gente, eu passei na UFMG pra Pedagogia, mas não passava pra outro curso!”. Já Amanda é ainda mais explícita ao avaliar as consequências de suas limitações acadêmicas sobre seu processo de escolha do curso superior:

Eu fui pegando aquele... aquele caderninho da Federal e fui olhando... candidatos por vaga, pontuação... ah, isso tudo eu olhei porque, assim, eu sou muito racional, falei: eu nunca vou tentar Medicina! Eu sei que eu não posso! Arquitetura eu não tentei porque eu sabia que não ia conseguir fazer prova de 
Física e Matemática aberta. Eu acho que, se eu tivesse condições, às vezes eu estaria fazendo Arquitetura hoje em dia.

Ainda em relação à escolha por Pedagogia, Amanda afirma que "se fosse pra qualquer outro curso eu não passaria, tenho plena consciência disso".

Sobre os critérios ou parâmetros que orientaram a decisão das alunas, outro ponto a ser considerado é que ambas relatam que tinham forte desejo de ingressar na UFMG. Tanto Telma quanto Amanda têm irmãos que realizaram ou realizam sua formação acadêmica nessa universidade, em Ciências Sociais e Direito, respectivamente. Em sua entrevista, Amanda declara: "Queria estudar aqui de qualquer jeito!". No caso de Telma, há uma cobrança explícita do pai pela UFMG: "te dou tudo, do bom e do melhor, em cursinho, escola, curso de inglês, essas coisas, mas vocês vão entrar na UFMG!'”. Ainda em relação a Telma, outro fator parece ter colaborado por esse seu anseio pela Federal. Essa estudante, no início de sua escolarização, foi aluna do Centro Pedagógico da UFMG e, em seu discurso, declara o forte desejo de "voltar" para essa instituição federal de ensino.

A escolha por Pedagogia, nesses dois casos, parece, portanto, poder, em grande medida, ser explicada pelas limitações acadêmicas das alunas, que restringiram suas escolhas viáveis no vestibular, e pela forte preferência pela Federal, que as leva a optar por essa universidade, mesmo que não nos cursos mais desejados. A Pedagogia surge, assim, como o caminho possível para o acesso a essa universidade. Teríamos, portanto, dois casos típicos do que é comumente chamado de "escolha pelo possível".

Essa interpretação não pode desconsiderar, no entanto, o fato de que uma "escolha pelo possível" dificilmente ocorre sem algum nível de interesse pelo objeto escolhido. Assim, embora as alunas não tenham manifestado precocemente gosto pela área e não tenham optado, inicialmente, pelo vestibular de Pedagogia, existem elementos nos relatos de ambas que indicam a existência, em suas trajetórias, de alguns vínculos significativos com a área de Educação.

Segundo Amanda, sua escolha acontece a partir de um estágio como professora de História, ocorrido meses antes do vestibular, em uma escola pública. Nos termos dela: "quando eu entrei, eu adorei! Hoje em 
dia, eu tô gostando mais de Pedagogia que de História (curso em que, como afirmado por ela, a aspiração inicial era ser pesquisadora) e vejo que meu negócio é trabalhar com educação, com isso mesmo". Já em relação a Telma, é especialmente interessante notar que, à "sombra" dessa escolha, existe uma mãe bem-sucedida e realizada na carreira de Pedagoga, e que apresentava um grande desejo de ver a filha nessa mesma profissão.

\section{CONSIDERACְÕES FINAIS}

Talvez a principal conclusão que se pode tirar deste trabalho é que a relação entre o gosto e as condições objetivas nas quais se encontram os indivíduos são mais complexos do que pode sugerir a explicação sociológica tradicional, sobretudo bourdieusiana, que tende a ver o gosto ou as preferências como produtos de uma adaptação ou de um ajustamento - incorporado na forma do habitus - dos agentes individuais ou coletivos às suas posições sociais objetivas.

Nos oito casos aqui analisados, o gosto aparece com uma relativa autonomia em relação às condições objetivas dos agentes. Ele tem uma história própria. Os sujeitos constituíram, em função de suas experiências positivas como alunos, de suas pequenas vivências profissionais bemsucedidas na área da Educação (antes da entrada no curso superior), do estabelecimento de laços de amizade, admiração e respeito com pessoas ligadas à área ou da própria experiência de terem uma mãe educadora (caso de duas alunas) um gosto mais ou menos forte pela educação.

É claro que a manifestação concreta desse gosto não é direta e nem livre de ambiguidades: sua manifestação e sua prevalência como fator definidor do ato de escolha parecem depender de uma série de fatores e circunstâncias. Antes de mais nada, os relatos deixam claro que as alunas tiveram de vencer o preconceito de suas famílias e de seu meio social mais amplo em relação ao curso de Pedagogia' ${ }^{9}$ Via de regra, esse curso não é visto por parentes e amigos como adequado ao perfil social e escolar relativamente alto das alunas. Essa pressão social parece ter impactado de diferentes maneiras as oito trajetórias estudadas. Nos dois primeiros casos, o gosto pela área de Educação parece ter sido inicialmente recalcado, para usar um termo psicanalítico. As alunas dizem que, no momento em que escolheram seu primeiro curso, não chegaram nem mesmo a pen- 
sar sobre a possibilidade de fazerem Pedagogia. Só bem mais tarde, ao enfrentarem dificuldades pessoais e profissionais decorrentes de suas escolhas iniciais e tentarem redirecionar suas trajetórias profissionais, elas reconhecem que sempre gostaram da área e que, por algum motivo, não deram vazão a esse interesse. Nos dois casos seguintes, a dificuldade de assumir a opção pela Pedagogia aparece de forma ainda mais clara. As alunas descrevem um preconceito fortíssimo das famílias em relação ao curso e à profissão docente, o que as leva a optar, inicialmente, por fazer o primeiro vestibular para outros cursos superiores. A decisão final pela Pedagogia só vem após serem reprovadas no vestibular e passarem um ano repensando sua decisão inicial: por meio de conversas com pessoas da área de Educação e mesmo com a ajuda de terapia, no caso de uma das alunas. Segundo as entrevistadas, foi só a partir desse período de crise e de profunda reflexão que elas conseguiram reafirmar, apesar dos preconceitos, seu verdadeiro gosto pela Pedagogia. No quinto e no sexto casos, acompanhamos novamente um embate entre o gosto pela área de Educação e as pressões sociais. As famílias desestimularam explicitamente a opção das filhas por Pedagogia. Nesses dois casos, no entanto, a força do gosto das alunas pela área prevaleceu e as duas fizeram vestibular apenas para esse curso, sendo aprovadas em sua primeira tentativa. Os dois casos finais, como foi discutido, são aqueles em que o gosto pela área de Educação aparece de forma menos evidente. As alunas só fazem a opção pela Pedagogia após terem sido reprovadas em vestibulares para vários outros cursos. Tem-se, portanto, algo próximo da chamada "escolha pelo possível". Mesmo nesses casos, no entanto, verificamos que, secundariamente, o gosto parece estar presente. Uma das alunas havia tido uma experiência profissional bem-sucedida na área educacional e a outra tinha como referência uma mãe pedagoga satisfeita com a profissão.

Em todos os casos, a escolha pela Pedagogia parece resultar de um jogo complexo, no qual se encontram um gosto mais ou menos forte pela área de Educação, expectativas e pressões familiares relacionadas à posição social mais elevada das entrevistadas, e circunstâncias específicas ligadas às trajetórias de vida das alunas. $\mathrm{Na}$ análise desse jogo, nenhuma das dimensões pode ser desprezada. Por um lado, em todos os casos, sobretudo nos seis primeiros, parece existir um gosto autêntico, que antecede o momento da escolha e que não se reduz a uma simples adaptação às condições objetivas. Por outro lado, há um papel claro das pressões de 
amigos e familiares, impedindo que esse gosto seja reconhecido e assumido plenamente pelas alunas desde o seu primeiro vestibular. Finalmente, não se pode negligenciar o peso de circunstâncias específicas vividas por algumas das alunas - problemas de adaptação a outros cursos, dificuldades de inserção em outro campo profissional, reprovação em outros vestibulares - que parecem ter contribuído para que o gosto pela área da Educação vencesse as resistências sociais e encontrasse condições para a sua realização.

Referências BALL, Stephen; DAVIES Jackie; DAVID Miriam.; REAY Diane. Décisions, différenciations et distinctions: vers une sociologie du choix des études supérieures. Revue Francaise de Pédagogie, n. 136, juillet/août/septembre, p. 65-75, 2001.

BRAGA, M. M.; PEIXOTO, M. C. L.; BOGUTCHI, T. F. Tendências da demanda pelo ensino superior: estudo de caso da UFMG. Cadernos de Pesquisa, n. 113, p. 129-152, 2001. BOURDIEU, Pierre. A distinção: crítica social do julgamento. Porto Alegre: Zouk, 2007. BOURDIEU, Pierre. Escritos de educasão. NOGUEIRA, Maria Alice; CATANI, Alfredo (Orgs.). 5 ed. Petrópolis: Vozes, 2003.

BOURDIEU, Pierre. A ilusão biográfica. In: FERREIRA, Marieta de Morais; AMADO, Janaína. (Org.) Usos e abusos da história oral. RJ: FGV, 1996. p. 183-191.

BOURDIEU, Pierre. Pierre Bourdieu. ORTIZ, R. (Org.). São Paulo: Ática, 1983.

DURU-BELLAT Marie.; MINGAT Alain. Les disparités de carrières individuelles a l'université : une dialectique de la sélection et de l'autosélection. L'Année sociologique, v. 38, p. 309-340, 1988.

DURU-BELLAT Marie.; MINGAT Alain. Comportement des bacheliers: modèle de choix de disciplines. Consommation, n. 3-4, 1979.

LAHIRE, Bernard. Homem plural: Os determinantes da ação. Petrópolis: Vozes, 2002.

LAHIRE, Bernard. De la théorie de l'habitus à une sociologie psychologique. In: LAHIRE, Bernard (Org.) Le travail sociologique de Pierre Bourdieu. Paris: La découverte, 1999.

LAHIRE, Bernard. Sucesso escolar nos meios populares: As razões do improvável. São Paulo: Ática, 1995.

NOGUEIRA, Cláudio M. M. Dilemas na análise sociológica de um momento crucial das trajetórias escolares: o processo de escolha do curso superior. Tese (Doutorado em Educação). Universidade Federal de Minas Gerais, 2004.

NOGUEIRA, Cláudio M. M. Desafios teóricos na análise sociológica de um momento crucial das trajetórias escolares: a escolha do curso superior. $29^{2}$ REUNIÃO ANUAL DA ANPOCS. Anais... Caxambu, 2005.

PAUL Jean-Jacques; SILVA, Nelson V. Conhecendo o seu lugar: a auto-seleção na escolha de carreira. Revista Brasileira de Política e Administração da Educaşão, v. 14, n. 1, p. 115-130, 1998.

RIBEIRO, Henrique M. F.; VIANA, Maria J. B. Um perfil sociológico do aluno atual do curso de Pedagogia da FAE/UFMG. Educação em Revista, v. 43. p. 111-135, jun. 2006.

SETTON, Maria G. J. A divisão interna do campo universitário: uma tentativa de classificação. Revista Brasileira de Estudos Pedagógicos, Brasília, v. 80, n. 196, p. 451-471, 2002. 
SETTON, Maria G. J. A particularidade do processo de socialização contemporânea. Tempo Social. Revista de Sociologia da USP, São Paulo, v. 17, n. 2, p. 335-350, 2005.

SINGLY, François de. A apropriação da herança cultural. Educação \& Realidade. v. 34, n. 1, jan./abr. p. 9-32, 2009.

\section{Notas}

${ }^{1}$ Ver, por exemplo: Duru-Bellat e Mingat (1998); Paul e Silva (1998); Ball et al. (2001). Para uma discussão geral sobre as pesquisas sociológicas sobre o processo de escolha do curso superior, ver Nogueira (2004; 2005).

2 Para uma discussão sobre a hierarquização social dos cursos superiores, ver: Setton (2002); Braga, Peixoto e Bogutchi (2001); Braga e Peixoto (2006). Sobre a relação entre a escolha e a rentabilidade econômica e simbólica associada aos cursos e às futuras profissões, ver, entre outros, Duru-Bellat e Mingat (1979).

3 De modo geral, os estudantes do curso de Pedagogia apresentam perfil social e escolar significativamente mais baixo que o da média dos estudantes da UFMG. Os dados do censo da universidade mostram, por exemplo, que, em 2006, enquanto $41,2 \%$ das mães de alunos da UFMG possuíam formação superior, esse percentual era de $11,9 \%$ entre aquelas cujos filhos cursavam Pedagogia diurno e $7,2 \%$ entre as dos alunos do noturno. Para um perfil sociológico dos alunos de Pedagogia, ver também: Ribeiro e Viana (2006). 4 Lahire $(1995$; 2002) chama a atenção exatamente para o fato de que os diferentes atributos utilizados para categorizar as famílias (tamanho, composição, capital econômico, cultural, etc.) ganham um significado específico quando considerados dentro de uma configuração familiar particular. O sentido e a importância de cada um desses atributos seriam definidos em função do modo específico como eles se conjugam com os demais no interior de cada família. Lahire ressalta também que as famílias normalmente são mais heterogêneas internamente do que tendemos a supor.

5 Para uma discussão sobre a complexidade do processo de transmissão da herança cultural familiar, ver, entre outros, Syngly (2009) e, novamente, Lahire (1995). Para uma discussão sobre o caráter híbrido dos babitus que se constituem a partir de múltiplas influências, ver Setton (2005).

6 Os resultados apresentados neste trabalho foram produzidos no interior de uma pesquisa mais ampla sobre o processo de escolha do curso de Pedagogia da Universidade Federal de Minas Gerais. Na primeira parte dessa pesquisa, partindo dos dados do Censo Socioeconômico da universidade (banco de dados sobre os alunos de graduação da UFMG) e da aplicação de um amplo questionário a 115 alunos do primeiro ano de Pedagogia, produziu-se uma caracterização sociológica geral dos estudantes e uma análise, também geral, do processo de escolha do referido curso. Na segunda parte da pesquisa, passou-se para uma análise mais detalhada desse processo decisório, por meio da identificação de dois subgrupos de alunos: um formado pelos 22 alunos com perfil social e com trajetória escolar mais favorável e outro, pelos 22 alunos com perfil social e escolar menos favorável. Dentro dessa segunda etapa da pesquisa, foram realizadas entrevistas em profundidades com parte dos alunos de cada subgrupo. 
7 Não se pode negligenciar a possibilidade de que o discurso das alunas sobre um gosto antigo pela educação possa ser, em parte, uma reconstrução a posteriori do passado, feita de modo a justificar e tornar coerentes as trajetórias de vida e as decisões tomadas no tempo presente. Sobre os riscos de uma "ilusão biográfica", ver Bourdieu (1996).

8 Não apenas as entrevistas analisadas neste trabalho, mas todo o conjunto de dados quantitativos e qualitativos produzidos durante a pesquisa mostra que a reação dos pais à escolha dos filhos está estreitamente relacionada à sua própria posição social. Os pais mais escolarizados e com nível socioeconômico mais alto reagem de forma mais negativa à escolha de Pedagogia, lamentando o fato de os filhos não terem escolhido cursos de maior prestígio. Os pais menos escolarizados e com nível socioeconômico mais baixo, ao contrário, mostram-se mais satisfeitos com a opção dos filhos.

9 O fato de ser um curso de Pedagogia da UFMG, umas das universidades de maior prestígio em Minas Gerais, minimiza parte dos preconceitos em relação ao curso. Vale lembrar que, em vários momentos das entrevistas, as alunas descrevem seu desejo e a pressão familiar para que entrassem na UFMG.

Recebido: 04/09/2009

Aprovado: 22/06/2010

Contato:

Universidade Federal de Minas Gerais

Faculdade de Educação

Av. Antônio Carlos, 6627

Belo Horizonte - MG

CEP $31270-901$ 